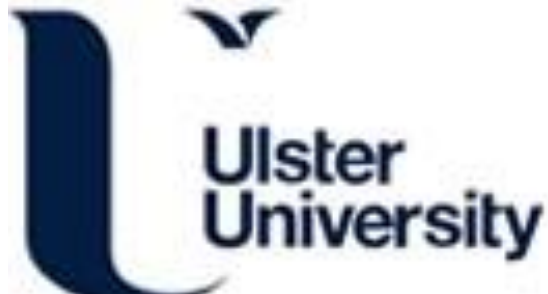

\section{A Severe Case of Spondylometaphyseal Dysplasia Algerian Type with Two Mutations in COL2A1}

Cammarata-Scalisi, F., Matysiak, U., Willoughby, C. E., Ruzaike, G., Cárdenas Tadich, A., Araya Castillo, M., Zara-Chirinos, C., Bracho, A., Avendaño, A., Jilani, H., \& Callea, M. (2021). A Severe Case of Spondylometaphyseal Dysplasia Algerian Type with Two Mutations in COL2A1. Journal of Pediatric Genetics. https://doi.org/10.1055/s-0041-1732474

Link to publication record in Ulster University Research Portal

\section{Published in:}

Journal of Pediatric Genetics

Publication Status:

Published online: $26 / 07 / 2021$

DOI:

10.1055/s-0041-1732474

\section{Document Version}

Author Accepted version

\section{General rights}

Copyright for the publications made accessible via Ulster University's Research Portal is retained by the author(s) and / or other copyright owners and it is a condition of accessing these publications that users recognise and abide by the legal requirements associated with these rights.

\section{Take down policy}

The Research Portal is Ulster University's institutional repository that provides access to Ulster's research outputs. Every effort has been made to ensure that content in the Research Portal does not infringe any person's rights, or applicable UK laws. If you discover content in the Research Portal that you believe breaches copyright or violates any law, please contact pure-support@ulster.ac.uk. 


\title{
A Severe Case of Spondylometaphyseal Dysplasia Algerian Type with Two Mutations in COL2A1
}

\author{
Francisco Cammarata-Scalisi ${ }^{10}$ Uta Matysiak ${ }^{2}$ Colin E. Willoughby ${ }^{3}$ Gunda Ruzaike ${ }^{2}$ \\ Antonio Cárdenas Tadich ${ }^{1}$ Maykol Araya Castillo ${ }^{4}$ Carmen Zara-Chirinos $^{5}$ Ana Bracho ${ }^{5}$ \\ Andrea Avendaño ${ }^{6}$ Houweyda Jilani ${ }^{7,8}$ Michele Callea $^{9}$ \\ ${ }^{1}$ Departamento of Pediatrics, Regional Hospital of Antofagasta, \\ Antofagasta, Chile \\ 2 Department of Pediatrics, Medical Center-University of Freiburg, \\ Faculty of Medicine, University of Freiburg, Freiburg, Germany \\ ${ }^{3}$ Genomic Medicine, School of Biomedical Sciences, Ulster University, \\ Northern Ireland, United Kingdom \\ ${ }^{4}$ Clinical Laboratory, Regional Hospital of Antofagasta, Chile \\ 5 Institute of Genetic Research, Faculty of Medicine, University of \\ Zulia, Maracaibo, Venezuela \\ J Pediatr Genet \\ Address for correspondence Francisco Cammarata-Scalisi, MD, \\ Pediatrics Service, Regional Hospital of Antofagasta, Azapa 5935, \\ Antofagasta 1240000 , Chile \\ (e-mail: francocammarata19@gmail.com). \\ ${ }^{6}$ Division of Medical Genetics, Department of Pediatrics, Faculty of \\ Medicine, University of Los Andes, Mérida, Venezuela \\ ${ }^{7}$ Genetic Department, Mongi Slim Hospital, Marsa, Tunisia \\ ${ }^{8}$ Faculty of Medicine of Tunis, University of Tunis El Manar, Tunisia \\ ${ }^{9}$ Division of Dentistry, Bambino Gesù Children's Hospital, IRCCS, \\ Rome, Italy
}

\begin{abstract}
Keywords

- skeletal dysplasia

- spondylometaphyseal dysplasia Algerian type

- COL2A1 gene

Spondylometaphyseal dysplasia Algerian type (MIM no.: 184253) is an uncommon autosomal dominant skeletal dysplasia caused by heterozygous mutations in the COL2A1 gene (MIM no.: 120140). In this case based review, we reported a 5-year-old boy with short stature, severe dorsolumbar scoliosis, lumbar hyperlordosis, short trunk, and severe genu valgum. Radiological examination showed platyspondyly, irregular metaphyseal radiolucencies intermingled with radiodensities, and corner fractures. The patient has a c.3275G > A; p.Gly1092Asp mutation in exon 47 of the COL2A1 gene and a variant of unknown significance in c.1366-13C $>A$ in intron 21 . This latter sequence variant could partially or completely disrupt the natural splice acceptor site of intron 21/exon 22 in the COL2A1 gene leading to a potential modification of the phenotypic severity.
\end{abstract}

\section{Introduction}

The term spondylometaphyseal dysplasia Algerian type (SMD-A; MIM no.: 184253) was introduced by Kozlowski et $\mathrm{al}^{1}$ who reported five cases in an Algerian family. Subsequently, Rybak et $\mathrm{al}^{2}$ reported a sporadic case in a Polish boy and considered SMD-A as a distinctive skeletal dysplasia. They also suggested that a case of SMD described by Schmidt et $\mathrm{al}^{3}{ }^{3}$ in 1963, represented the same entity. Finally, Matsubayashi et $\mathrm{al}^{4}$ reported a Japanese boy with a heterozygous missense mutation in COL2A1 gene, with the SMD-A phenotype and clarified that SMD-A is a variant within the type-II collagenopathies. $^{5}$

received

February 10, 2021

accepted after revision

June 7,2021
Here, we reported the clinical and radiological findings of a new sporadic case of SMD-A in a 5-year-old boy with two variants in the COL2A1 gene.

\section{Clinical Manifestation}

The patient was a Venezuelan boy referred to the Medical Genetic Unit because of short stature and bone deformity at 5 years of age. He was born to healthy nonconsanguineous parents. The family history was negative. Maternal urinary tract infection was the only prenatal disturbance. The boy was delivered vaginally at $38^{6 / 7}$ weeks of gestation. His birth length was $45.0 \mathrm{~cm}$ ( -3.3 standard deviation [SD]), and

(c) 2021. Thieme. All rights reserved. Georg Thieme Verlag KG, Rüdigerstraße 14, 70469 Stuttgart, Germany
DOI https://doi.org/ 10.1055/s-0041-1732474. ISSN 2146-4596. 
weight was $4.5 \mathrm{~kg}$ (3.6 SD). He had a unilateral inguinoscrotal hernia which was surgically corrected at 9 months of age. Recurrent pneumonia was frequent and required another hospitalization.

Except for late walking at the age of 30 months, his psychomotor development was normal. Cardiovascular evaluation showed a small atrial septal defect that was closed spontaneously. His abdominal and renal ultrasound studies were normal.

When he was assessed at the age of 5 years of age, his height was $70 \mathrm{~cm}(-10.8 \mathrm{SD})$ and weight was $12.7 \mathrm{~kg}(-2.6$ SD). His facial features were unremarkable, except for a broad forehead. Short neck and trunk with severe dorsolumbar scoliosis and lumbar hyperlordosis were also evident. His femora were kept in flexion and there was a wind-swept deformity of the knees. He was also noted to have brachydactyly and camptodactyly. His cognitive development was within the normal range, and his ophthalmologic and audiological examinations were normal. Routine blood and urinary studies disclosed a phosphate level of $7.30 \mathrm{mg} / \mathrm{dL}$ (normal range: $3.4-6.8 \mathrm{mg} / \mathrm{dL}$ ).

\section{Diagnosis}

Radiological examination showed a normal skull, platyspondyly, dorsolumbar scoliosis, and lumbar hyperlordosis. The ilia were broad and short in their vertical dimension. The proximal femoral epiphyses were in severe varus position and mottled in appearance. His right knee was in valgus position, the left mildly bowed. The metaphyseal margins of the long bones were irregular with intermingled radiolucencies and radiodensities (-Fig. 1). Corner fractures were noted and the short tubular bones were minimally affected.

Blood samples from the patient were obtained with informed consent from his mother, and genomic DNA was extracted using standard methods. ${ }^{6}$ Coding exons and their intron-exon boundaries were amplified by polymerase chain reaction and sequenced to screen for COL2A1 mutations.

We identified two variants, one clearly pathogenic and second potentially pathogenic in COL2A1 gene, c.3275G $>$ A; p.G1092D in exon 47 and c.1366-13C > A in intron 21.

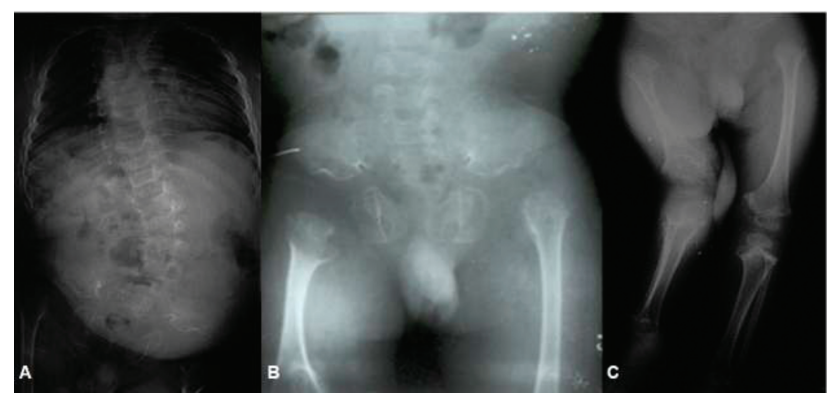

Fig. 1 (A) Radiological examination showed a dorsolumbar scoliosis (B) The ilia were broad and short in their vertical dimension. The proximal femoral epiphyses were in severe varus position and mottled in appearance. (C) The right knee was in valgus position, the left mildly bowed. The metaphyseal margins of the long bones were irregular with intermingled radiolucencies and radiodensities.

\section{Discussion}

SMD-A is characterized by short-trunk dwarfism, scoliosis, kyphosis, and severe leg deformities, all of which worsen with age. ${ }^{1,3,4}$ Myopia is observed but was not found in our patient. Radiologically, kyphoscoliosis, moderate platyspondyly, and metaphyseal anomalies are prominent. Epiphyseal ossification is retarded and mildly irregular, most conspicuously in the capital femora epiphyses that may be irregularly structured and in severe varus position. ${ }^{1,4}$

SMD-A belongs to the subgroup of type-II collagenopathies with marked metaphyseal involvement which also include Strudwick's type, dysspondyloenchondromatosis, and some cases of SMD corner fracture type. ${ }^{7}$ Its distinction as a separate entity can be challenged but may be justified by the severe involvement of the knee joints. COL2-related SMDs must be differentiated from other SMD, notably SMD corner-fracture type, Kozlowski's SMD, axial SMD with cone-rod dystrophy, and odontochondrodysplasia. ${ }^{8}$

Sequencing analysis of COL2A1 gene identified that our patient carries two variants, one clearly pathogenic and the second potentially pathogenic. The first one, c.3275G $>$ A, is a transition mutation involving a change of a guanine by an adenine at codon 1092 in exon 47, leading to a missense mutation in the protein p.G1092D (rs794727684). This variant was not fully described previously, although it was annotated in the ClinVar database (https://www.ncbi.nlm.nih.gov/clinvar/) as likely pathogenic for Stickler's syndrome type 1 (RCV000322756.1) and spondyloepiphyseal dysplasia congenital (RCV000178624.1). To determine the pathogenicity of $\mathrm{p}$. G1092D, web-based packages were as follows: SIFT (v4.0.3) classified the mutation as deleterious (score: 0 , median: 4.32 ); and PolyPhen-2 considered this mutation as probably damaging with a score of 0.999 (sensitivity 0.14 ; specificity 0.99 ) and that glycine in 1092 position is fully conserved in different species. ${ }^{9}$ The Provean web server which calculates the functional effect of missense and indels mutations predicted a deleterious effect for p.G1092D with a score of -6.488 (cutoff $=-2.5$ ); and Mutation Taster program (v2013) classified this variation as a disease-causing mutation $(p=1) .^{10,11}$

The second variant, c.1366-13C $>\mathrm{A}$, is a base substitution located in intron 21 at 13 bp downstream from acceptor site splicing. This variant is annotated in ClinVar as of uncertain significance associated with collagenopathies type II (RCV000364110.1) and Stickler's syndrome (RCV000269517.1). It is a known dbSNP (144): rs200984998 (MAF/MinorAlleleCount: $\mathrm{T}=0.002 / 0$ ) and reported by Exome Variant Server (http://evs.gs.washington.edu; ID number: ESP6500SIV2) in European American population with a frequency of $0.07 \%$ but not in African American population. According to the ExAC Browser Beta (http://exac.broadinstitute.org/), this variant was found in different populations: American, 0.043\%; European nonFinnish, 0.093\%; Finnish, 0.15\%; and other populations, $0.11 \%$. Mutation taster classified this change as a polymorphism with 0.17 and 0.001 scores in PhyloP and PhastCons, respectively. Moreover, this variant was reported in 1000 Genomes Project Phase 3 and was identified in 
heterozygous state in the Colombian population (with a 0.011 genotype frequency). ${ }^{12}$ It should be noted that the paternal grandparents of the patient are from Colombia. Furthermore, this change was analyzed using the Human Splicing Finder predicting no significant splicing motif alteration. ${ }^{13}$ However, c. $1366 \mathrm{C}>\mathrm{A}$ is suspected to be pathogenic because of predicted effect on the natural splice acceptor site of intron 21/exon 22 using the splicing tool of the Alamut Visual software (Interactive Biosoftware-a Sophia Genetics Company, Rouen, France). The phenotypic effect of c.1366C $>$ A cannot be fully determined. An attempt was made to study both parents, but they were not available by the time the results from the study were obtained. The c.1366-13C > A mutation, may be a potential modifier of the patient's phenotype, explaining the severe clinical manifestation or just be a polymorphism inherited from a healthy parent.

The most common mutations in COL2A1 occur in the triple-helical domain. A mature type-II collagen is a homotrimeric protein, each chain is composed of 1,014 amino acids with a glycine in every third position which is a key amino acid to the helix folding and stability. ${ }^{14,15}$ The p. G1092D mutation identified in our patient is located in this domain and affects a glycine. Two main molecular mechanisms are described in collagenopathies type 2. Dominant-negative mutations, involving the substitution of glycine in the triple helix, which dramatically impair mature type-II collagen assembly and stability. An additional mechanism is haploinsufficiency, produced by nonsense mutations or out-of-frame deletions, leading to a premature termination codon; consequently, these mutations lead to a reduction in protein synthesis. ${ }^{5}$

Two different mutations in a patient with an autosomal dominant disease such as collagenopathies type 2 is not common. This phenomenon displays two possible scenarios. The first one is that the intronic mutation could be acting like a genetic modifier, resulting in a more severe phenotype in this patient. The second scenario is that the mutations are not in cis but trans, and so the mutations were inherited in an autosomal recessive fashion. However, in other type-II collagenopathies, a double heterozygous mutation was previously reported in a Japanese patient with spondyloepiphyseal dysplasia congenital phenotype. In this case, both mutations were located in the coding sequence for the triple helix domain and a severe phenotype was also reported. ${ }^{16}$

An additional mutation was described in another Japanese patient with SMD-A phenotype who presented with short stature, severe leg deformity, severe genu valgum, myopia, and hearing impairment. This patient had a heterozygous missense mutation located in the triple helical domain (p.G861V) in COL2A1. Regarding skeletal alterations, our patient showed a more severe phenotype than the previously reported patient. However, neither myopia nor deafness was described in our patient. ${ }^{4}$

\section{Conclusion}

This study reports the clinical and radiological findings of a new case of SMD-A presenting new COL2A1 genetic variants at the molecular level, highlighting a severe phenotype and potential differential diagnoses.

\section{Funding \\ None.}

\section{Conflict of Interest}

None declared.

\section{References}

1 Kozlowski K, Bacha L, Massen R, Ayati M, Sator S, Brahimi L. A new type of spondylo-metaphyseal dysplasia-Algerian type. Report of five cases. Pediatr Radiol 1988;18(03):221-226

2 Rybak M, Foley TP, Kozlowski K. Spondylo-metaphyseal dysplasia Algerian type: confirmation of a new syndrome. Am J Med Genet 1991;40(03):304-306

3 Schmidt BJ, Becak W, Becak ML, et al. Metaphyseal dysostosis. Review of literature; study of a case with cytogenetic analysis. J Pediatr 1963;63:106-112

4 Matsubayashi S, Ikema M, Ninomiya Y, Yamaguchi K, Ikegawa S, Nishimura G. COL2A1 mutation in spondylometaphyseal dysplasia Algerian type. Mol Syndromol 2013;4(03):148-151

5 Barat-Houari M, Sarrabay G, Gatinois V, et al. Mutation update for COL2A1 gene variants associated with type II collagenopathies. Hum Mutat 2016;37(01):7-15

6 Sambrook J, Fritsch EF, Maniatis T. Molecular Cloning: A Laboratory Manual. 2nd ed. New York, NY: Cold Spring Harbor Laboratory Press; 1989

7 Mortier GR, Cohn DH, Cormier-Daire V, et al. Nosology and classification of genetic skeletal dysplasias. Am J Med Genet 2019;179:2393-2419

8 Spranger JW, Brill PW, Hall C, Nishimura G, Superti-Furga A, Unger S. Bone Dysplasias: An Atlas of Genetic Disorders of Skeletal Development. 4th ed. Oxford, United Kingdom: Oxford University Press; 2018

9 Adzhubei IA, Schmidt S, Peshkin L, et al. A method and server for predicting damaging missense mutations. Nat Methods 2010;7 (04):248-249

10 Choi Y, Chan AP. PROVEAN web server: a tool to predict the functional effect of amino acid substitutions and indels. Bioinformatics 2015;31(16):2745-2747

11 Schwarz JM, Cooper DN, Schuelke M, Seelow D. MutationTaster2: mutation prediction for the deep-sequencing age. Nat Methods 2014;11(04):361-362

12 Auton A, Brooks LD, Durbin RM, et al; 1000 Genomes Project Consortium. A global reference for human genetic variation. Nature 2015;526(7571):68-74

13 Desmet FO, Hamroun D, Lalande M, Collod-Béroud G, Claustres M, Béroud C. Human Splicing Finder: an online bioinformatics tool to predict splicing signals. Nucleic Acids Res 2009;37(09):e67

14 Zhang B, Zhang Y, Wu N, Li J, Liu H, Wang J. Integrated analysis of COL2A1 variant data and classification of type II collagenopathies. Clin Genet 2020;97(03):383-395

15 Deng H, Huang X, Yuan L. Molecular genetics of the COL2A1related disorders. Mutat Res Rev Mutat Res 2016;768:1-13

16 Kawano O, Nakamura A, Morikawa S, Uetake K, Ishizu K, Tajima T. Spondyloepiphyseal dysplasia congenita caused by double heterozygous mutations in COL2A1. Am J Med Genet A 2015;167 (07):1578-1581 